\title{
Evaluation of Arterial Hypertension Care in Four Brazilian Metropoles
}

\author{
Oswaldo Yoshimi Tanaka, ${ }^{1 *}$ Tereza Etsuko Costa Rosa, ${ }^{2}$ Tarcísio Laerte Gontijo, ${ }^{3}$ Marília Cristina Prado Louvison ${ }^{4}$ \\ ${ }^{1}$ Department of Policy, Management and Health, School of Public Health, University of São Paulo, Brazil \\ ${ }^{2}$ Researcher, Unit in Health Practices, Health Institute, Brazil \\ ${ }^{3}$ Federal University of São João del-Rei, Divinópolis MG, Brazil \\ ${ }^{4}$ Epidemiology and Information Coordination, City of São Paulo SP, Brazil
}

Keywords: Hypertension, Echocardiogram, morbidity and mortality, pharmacological therapy, therapeutic measures, Health Care

\section{Case Report}

Hypertension $(\mathrm{AH})$ is one of the most prevalent chronic diseases in Brazil, which, in 2018, affected about $24.5 \%$ of the adult population, reaching $59.3 \%$ of people aged 65 and over. (Ministry of Health 2020) ${ }^{1}$ These levels of prevalence and with an increasing trend have a major impact on morbidity and mortality, with high social cost. In this context, the Unified Health System (SUS) has been developing a strategic action plan based on conceptual bases that involve a comprehensive approach to chronic non-communicable diseases, especially $\mathrm{AH}$, at all levels of activity (promotion, prevention and comprehensive care and organization health services for the care of patients with chronic diseases). The guidelines of the Strategic Action Plan recommend that the care offered should use, in addition to pharmacological therapy, educational actions to change lifestyle (encouraging the practice of physical activity, the consumption of healthy foods and the reduction of salt consumption), monitoring the disease by means of routine examinations and searching for damage to a target organ (ECG and Echocardiogram) ${ }^{2}$ in specific populations. In addition to this set of technically oriented resources and therapeutic measures, another aspect, fundamental to the effectiveness of the comprehensive care offered, is the bond or the ability of the Primary Health Care(PHC) team to be identified by the person living with $\mathrm{AH}$ as a regular source of care, as a place that it is possible to maintain the adherence; as well as the ability/qualification of the unit's staff to be recognized as a place for provide information between different services to meet that user's health needs. ${ }^{3,4}$ Thus, PHC, a gateway, must have the ability to guarantee access to the various points of care, following the rational organization of the system, ${ }^{5}$ to respond in a timely manner to a user's demand and to carry out a referral for appropriate and necessary care. ${ }^{6}$ In addition, the idea of access to ECG should include the system's organizational availability, ${ }^{7}$ or convenience, ${ }^{5}$ related to the waiting time for consultations or exams.

However, we understand that comprehensive and quality health care depends on the deliberate organization of different health care strategies, especially in PHC, which is considered the preferred gateway for the system, the organizer of the Health Care

\begin{tabular}{|l|l|}
\hline Quick Response Code: & *Corresponding author: Oswaldo Yoshimi Tanaka, Department of Policy, Management and \\
Health, School of Public Health, University of São Paulo. Av. Dr. Arnaldo 715, Cerqueira Cezar. \\
01246-904 São Paulo SP Brazilx \\
Received: 23 October, 2020 \\
Citation: Oswaldo YT, Tereza ECR, Tarcísio LG, Marília CPL. Evaluation of Arterial Hyperten- \\
sion Care in Four Brazilian Metropoles. SOJ Cardio Curr Trend Surg. 2020;1(1):1-2. D0I: \\
10.53902/SOJCCTS.2020.01.000502
\end{tabular}


Network (RAS) and care coordinator. To evaluate AH care it was developed a cross-sectional study applying in a multiple analytical model by triangulating exploring different sources of information. IT was developed a comparative analysis of systemic arterial hypertension care in four Brazilian cities, with more than one million inhabitants. The municipalities of Campinas, Fortaleza, Porto Alegre and São Paulo were selected for their population magnitude and because their importance within the national health system. For the other hand, their heterogeneity composition and organization of health services was a variable to analyze the differences in PHC and in Specialized Care articulation. Secondary data were extracted from the official SUS information systems and the primary data were collected by questioning key informants from each municipality. IT was also applied a questionnaire to patients with $\mathrm{AH}$ living in the municipalities, that have been forwarded to the cardiologist by the PHC.

With some exceptions, according to the parameters of the Ministry of Health, health care coverage indicators, between 2009 and 2014, showed an excess supply with regard to cardiac consultation and echocardiography for the population in the municipalities. However, it was observed that there was no corresponding improvement in the quality of comprehensive care for these people, indicating that hypertensive patients now have more access to services directed to care in acute conditions. Interviews were conducted with 2019 users of specialized care services in the four cities under study. For the assessment of care and adherence, we used: orientation of receiving low-salt dietary guidance for the control of AH and the continuity of PHC follow-up after consultation with the cardiologist. The results indicate similar trends in different regions of the country, northeast represented by the city of Fortaleza and southeast, by Campinas. It was observed that in both cities, the health care orientation was about 50\% lower, compared to São Paulo. The PHC adherence chance, after consultation with the cardiologist, was approximately 2 times lower, compared to São Paulo. Regarding to the accessibility to specialized care, approximately $60 \%$ answered that they had waited more than 30 days to make an appointment with the cardiologist, however with no significant differences between cities.

IT is concluded that there are obstacles in the access and a fragile organizational flows for specialties from the PHC, although a qualified reception promote the users adherence In Brazil. The Unified Health System (SUS), implemented since the 1980s, allowed to reach access expansion to health services, in particular PHC, but retained structural fragmentation and segmentation in organization and provision of services, with lack of financial support. ${ }^{8,9}$

\section{Acknowledgments}

None.

\section{Funding}

None.

\section{Conflicts of interest}

Author declares that there is no conflict of interest.

\section{References}

1. Health Ministry. Brazil. 2020.

2. Radigonda B, Souza RKT, Junior LC, et al. Assessment of the follow-up of adult patients with arterial hypertension and/or diabetes mellitus by the Family Health Strategy and identification of associated factors in the city of Cambé, Brazil, 2012. EpidemiolServ Saúde. 2016;25(1):115-126.

3. Cunha EM, Giovanella L. Longitudinality/continuity of care: identifying dimensions and variables to the evaluation of Primary Health Care in the context of the Brazilian public health system. CiencSaúdeColetiva. 2011;16(Supl.1):1029-1042.

4. Oliveira GMM, Mendes M, Malachias MVB, et al. Guidelines for Arterial Hypertension Management in Primary Health Care in Portuguese Language Countries. Arq Bras Cardiol. 2017;109(5):389-396.

5. Sanchez RM, Ciconelli RM. The concepts of health access. Rev Panam Salud Publica. 2012;31(3):260-268.

6. Starfield B. Atenção Primária: equilíbrio entre necessidades de saúde, serviços e tecnologia. Brasília: UNESCO, Ministério da Saúde, 2002.

7. Conill EM, Fausto MCR, Giovanella L. The contribution of comparative analysis to a comprehensive evaluation framework for primary care systems in Latin America. Rev Bras SaúdeMatern Infant. 2010;10(Supl.1):S15-S27.

8. Carrilo Roa A, AlfaroCantón G, Ferreira MRJ. Os sistemas de saúde na América do Sul: caraterísticas e reformas. Sistema de saúde no Brasil: organização e financiamento/Rosa Maria Marques, Sérgio Francisco Piola, AlejandraCarrillo Roa (Organizadores). Rio de Janeiro: ABrES ; Brasília : Ministério da Saúde, Departamento de Economia da Saúde, Investimentos e Desenvolvimento; OPAS/OMS no Brasil 2016;260

9. Macinko J, Starfield B, Shi L. The contribution of primary care systems to health outcomes within Organization for Economic Cooperation and Development (OECD) countries, 1970-1998. Health Serv Res. 2003;38(3):831-365. 